GRAPHICAL PRESENTATION OF BETWEEN GROUP ANALYSIS

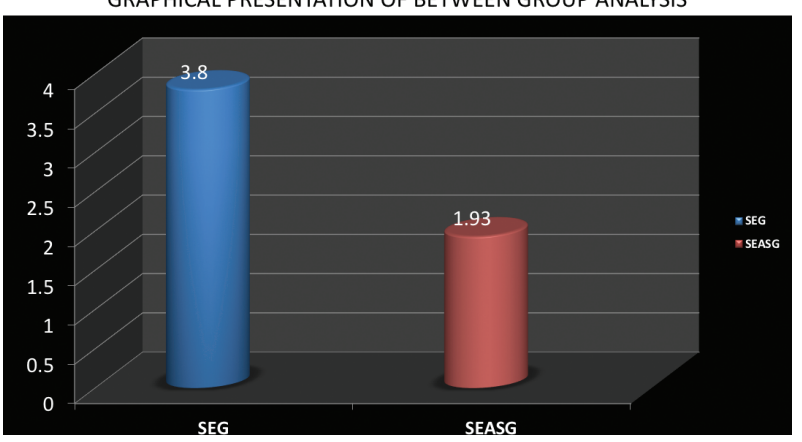

Disclosure of Interests: None declared

DOI: 10.1136/annrheumdis-2019-eular.7716

\section{AB1376-HPR ROLE OF NURSE-LED TELEPHONE FOLLOW UP TO ENHANCE AND SUBSEQUENTLY MAINTAIN HIGH LEVEL OF ADHERENCE TO OSTEOPOROSIS PROPHYLAXIS MEDICATIONS: A PROSPECTIVE COHORT STUDY OF PATIENTSWITH POLYMYALGIA RHEUMATICA AND GIANT CELL ARTERITIS}

Pia Toftegaard ${ }^{1},{ }^{1,2}$ Amir Emamifar ${ }^{3}$, Alexandra Brink Walling ${ }^{1}$, Susanne Højmark Jakobsen ${ }^{1}$, Peter Thye-Rønn ${ }^{2,3}$. 'Svendborg Hospital, Rheumatology, Svendborg, Denmark; ${ }^{2}$ University of Southern Denmark, Clinical Research, Odense, Denmark; ${ }^{3}$ Svendborg Hospital, Diagnostic Center, Svendborg, Denmark

Background: Poor adherence to the osteoporosis prophylaxis medications has been reported before, which may result in treatment failure. ${ }^{1}$ However findings of previous studies are controversial. ${ }^{1,2}$

Objectives: To investigate the role of nurse-led telephone follow-up to increase the level of adherence to osteoporosis prophylaxis medications in patients with newly diagnosed Polymyalgia Rheumatica/Giant Cell Arteritis (PMR/GCA).

Methods: This is an ongoing 1-year prospective cohort study. 37 consecutive steroid treated patients with newly diagnosed PMR/GCA were included. Patients were seen by the physicians at baseline, $1^{\text {st }}$ and $4^{\text {th }}$ month, where they were interviewed about their compliance towards osteoporosis prophylaxis medications, i.e. Calcium/Vitamin D supplements and Bisphosphonates (if Tscore $\leq-1$ ), using a standardized questionnaire Patients were therefore categorized as $100 \%, 50-100 \%,<50 \%$ adherent or non-adherent to the prescribed drugs. Every individual patient were contacted by our nurses one week after treatment initiation, and subsequently one month after physician visit to evaluate the effect of treatment, compliance to the medications and possible drugs side effects.

Results: $85.3 \%$ and $75.8 \%$ of the patients were completely adherent to their osteoporosis medications at $1^{\text {st }}$ and $4^{\text {th }}$ months of treatment initiation, respectively. (figure 1) The difference between level of adherence to the osteoporosis medications at $1^{\text {st }}(=$ week 4$)$ and $4^{\text {th }}$ month (=week 16) was not statistically significant. ( $P$ value:0.369). Decreased adherence in the patients was mainly due to forgetfulness.

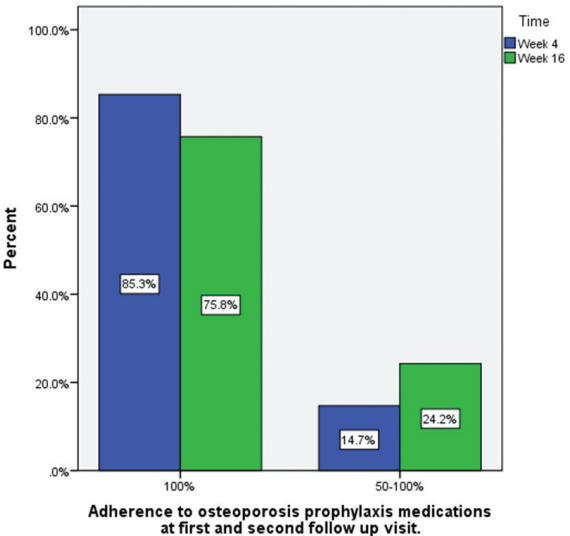

at first and second follow up visit.
.
Conclusion: Compared to the earlier findings we found a higher level of adherence in this group of patients. Nurse-led telephone follow up as well as educating the patients respecting the importance of the osteoporosis medications for preventing steroid related side effects, may enhance and subsequently maintain high level of adherence to the osteoporosis medications. Our findings are in line with our earlier study indicating a high level of adherence to the osteoporosis medications in PMR/GCA patients. $^{2}$

\section{REFERENCES}

[1] Rossini $M$, et al. Determinants of adherence to osteoporosis treatment in clinical practice. Osteoporos Int. 2006;17:914-21.

[2] Emamifar A, et al. Level of Adherence to Prophylactic Osteoporosis Medication amongst Patients with Polymyalgia Rheumatica and Giant Cell Arteritis: A Cross-Sectional Study. International Journal of Rheumatology. 2015;2015:783709.

Disclosure of Interests: None declared

DOI: 10.1136/annrheumdis-2019-eular.5091

\section{AB1377-HPR PATIENT ACTIVATION MEASURE IN PATIENTS WITH RHEUMATOID ARTHRITIS}

Laura Villarreal ${ }^{1}$, Fernando Rodriguez ${ }^{2}$, Pedro Santos-Moreno ${ }^{3}$, Diana BuitragoGarcia ${ }^{4} .{ }^{1}$ Biomab - Center for rheumatoid arthritis, Psychology, Bogotá, Colombia; ${ }^{2}$ Biomab - Center for rheumatoid arthritis, Patient program coordinator, Bogotá, Colombia; ${ }^{3}$ Biomab - Center for rheumatoid arthritis, Rheumatology, Bogotá, Colombia; ${ }^{4}$ Biomab - Center for rheumatoid arthritis, Nursing research, Bogotá, Colombia

Background: The Patient Activation Measure (PAM) is a 13-item measure that assesses patient knowledge, skill, and confidence for self-management. The measure was developed using Rasch analyses and is an interval level, unidimensional, Guttman-like measure. The current analysis is aimed at reducing the number of items in the measure while maintaining adequate precision(1). A Spanish adaptation of the scale was performed in 2017.

Objectives: To determine the level of activation, knowledge and skills for self-management in patients with Rheumatoid Arthritis

Methods: We performed a quantitative, observational, cross-sectional, and questionnaire-based study, convenience sampling was used. Participants were recruited in a specialized RA center, during a patients meeting. We applied the PAM-13 scale validated in Spanish. The scale has a score from 1 to 4 divided in four levels where level 1 represents a disengaged patient and suggests that the doctor is in charge of their health; level 2 : the patient becomes aware but struggling; level 3: The patient is taking action and considers himself as a part of the healthcare team, and level 4 represents a patient that maintains behaviors and pushes forward. The maximum score is 52 points.

Results: 322 patients participated, 23 patients generated incomplete PAM scores (response rate 92\%) and were excluded. From total $93 \%$ of patients were women. Mean age was 60 years 10; mean PAM-13 Was 19.83 6.16. In our study $68 \%$ of patients were in level 2 according to PAM-13 scale which means that they are becoming aware of their knowledge, skills and self-management but are still struggling. See table 1 . In average $80 \%$ of patients answered each question to be in level 1 or 2 , $15 \%$ in level 3 and only $5 \%$ in level 4 .

\begin{tabular}{lcc}
\hline LEVEL & $\mathrm{n}$ & $\%$ \\
\hline Level 1 & 59 & 19.73 \\
Level 2 & 204 & 68.23 \\
Leve 3 & 34 & 11.37 \\
Level 4 & 2 & 0,67 \\
\hline
\end{tabular}

Conclusion: This is the first study in our country where the Patient Activation Measure is applied in patients with rheumatoid arthritis. Thus, it might be useful to implement patient activation monitoring, since the level of activation is low in patients with RA.

Disclosure of Interests: Laura Villarreal: None declared, Fernando Rodriguez: None declared, Pedro Santos-Moreno Grant/research support from Dr Santos has received research grants from Janssen, Abbvie and UCB, Speakers bureau: Dr Santos has received speaker fees from Sanofi, Lilly, Bristol, Pfizer, Abbvie, Janssen and UCB, Diana Buitrago-Garcia: None declared

DOI: 10.1136/annrheumdis-2019-eular.7269 